\title{
DERECHO Y POLÍTICAS AMBIENTALES EN LAS ISLAS BALEARES
}

\section{DRET I POLÍTIQUES AMBIENTALS A LES ILLES BALEARS}

\author{
JOSEP MANUEL GÓMEZ GONZÁLEZ \\ Jefe de Servicio de Ordenación del Territorio \\ Departamento de Territorio e Infraestructuras. Consejo Insular de Mallorca
}


Sumario: 1. Introducción. 2. Medidas urgentes para la reactivación económica después del COVID-19. 3. Modificación y texto refundido de la Ley 12/2016 de evaluación ambiental. 4. Efectos del estado de alarma sobre el medio ambiente.

\section{INTRODUCCIÓN}

No hace falta abundar demasiado en el hecho de que la pandemia provocada por el SARS-CoV-2 ha condicionado completamente la actividad normativa ambiental también en las Illes Balears. Si tenemos en cuenta que las grandes iniciativas ya fueron aprobadas antes de concluir el año 2019 y relatadas en la crónica correspondiente, y que apenas ha podido arrancar el curso parlamentario del primer cuatrimestre del 2020, tenemos muy poco material para desarrollar nuestro apartado sobre las políticas ambientales del semestre, ni que sea retrasando al. máximo la entrega de esta crónica. La mayoría de las acciones se han volcado en el tratamiento de la pandemia y los borradores de disposiciones que se están preparando para la vuelta a la "nueva normalidad" parece que marginan por completo la dimensión ambiental dado que priman la recuperación y diversificación económica por encima de todo lo demás. Seguramente en la próxima crónica tendremos espacio y tiempo para analizar lo que se nos viene encima, pero por lo poco que he podido ver circulando en manos de funcionarios, será la revelación de un enorme despropósito ambiental con el que deberemos lidiar. No será ni la primera vez ni la última que para salir de una crisis la gran víctima acabe siendo nuestro entorno, el medio en el que vivimos. La emergencia climática será solamente un debilitado eco lejano y los llamados "nuevos paradigmas" un simple espejismo.

Pasemos, pues, a ver que escasas novedades podemos destacar en el extraño y excepcional escenario de este semestre.

\section{MEDIDAS URGENTES PARA LA REACTIVACIÓN ECONÓMICA DESPUÉS DEL COVID-19}

Sobre esta cuestión apenas podemos remitirnos a las crónicas periodísticas parlamentarias, al visionado de las discusiones en el pleno del Parlamento y a lo manifestado en ruedas de prensa, pero se ha hecho público que el Gobierno de la Comunidad Autónoma está preparando la redacción de un Decreto Ley de medidas urgentes destinado a la reactivación económica y a paliar los perjuicios 
económicos y sociales de la COVID-19. En el documento se incorporarán una batería de propuestas de simplificación y agilización administrativa, de regularización de actividades e instalaciones, de incentivación de proyectos industriales estratégicos y de diversificación económica, con la intención inicial de reducir la fuerte dependencia económica del sector turístico. en términos de PIB. También, es cierto, se barajan ayudas y medidas que pretenden alcanzar a las capas más vulnerables de la sociedad.

Como hemos apuntado, deberemos analizar en una próxima crónica las consecuencias que todo ello comportará sobre el medio ambiente y, especialmente, sobre la normativa de protección de este. Una de las tendencias apuntadas en el Decreto Ley es la de la ordenación directa de aspectos territoriales, urbanísticos y de orden sectorial, alterando la sistemática clásica basada en instrumentos articulados entorno a un sistema jerárquico compuesto por subsistemas dependientes. La experiencia nos enseña que alterar cualquier disposición sistemática e interdependiente comporta olvidos, antinomias, conflictos normativos y superposición de supuestos, probablemente esto es lo que también va a suceder ahora.

\section{MODIFICACIÓN Y TEXTO REFUNDIDO DE LA LEY 12/2016 DE EVALUACIÓN AMBIENTAL}

La Disposición final tercera de la Ley 9/2018 de 31 de julio, por la que se modificó la Ley 12/2016, de 17 de agosto, de evaluación ambiental de las Illes Balears, obligaba a la redacción de un texto refundido de esta Ley, texto que comenzó a redactarse a finales de 2019 y que incorporaba el contenido de la sentencia del Tribunal Constitucional de 3 de octubre de 2019, corrigiendo unos aspectos puntuales de la ley por motivos competenciales derivados de la legislación básica estatal en la materia.

El mismo octubre de 2019 se inició un trámite de información pública sobre la propuesta del texto refundido, propuesta que ahora se va a ver alterada por algunas modificaciones que acompañarán al Decreto Ley en redacción. Este texto refundido empezaba a ser necesario a pesar de la juventud de la norma, y es que, lo cierto es que la dinámica legislativa instalada en esta comunidad autónoma implica una hiperactividad normativa que genera cambios continuados 
en la legislación hasta el punto de que cuesta mucho saber en cada caso que régimen impera; y no solo esto, el gran problema son los conflictos de normas que aparecen, tal y como hemos apuntado en el apartado anterior. El negocio de los textos consolidados y comentados se encuentra en auge.

\section{EFECTOS DEL ESTADO DE ALARMA SOBRE EL MEDIO AMBIENTE}

Otro de los efectos experimentados a lo largo de estos meses es el de la regeneración de determinados bienes ambientales. La parada realizada como consecuencia del confinamiento ordenado por la declaración del estado de alarma ha provocado una significativa disminución en la contaminación atmosférica, una recuperación de entornos naturales y seminaturales, especialmente en los alrededores de las ciudades y pueblos, así como una mejoría en hábitats sensibles a la fauna, especialmente en zonas de cría y reproducción de aves.

Buena parte de estos efectos se han puesto de manifiesto en nuestros espacios naturales protegidos, donde la ausencia de frecuentación humana está provocando un mayor reparto territorial de la fauna. Se han detectado movimientos de fauna silvestre en lugares donde hacía años que no se producían; se reporta un cambio de hábitos de alimentación de aves marinas, dado que la parada ha provocado un efecto reserva en esta época del año verdaderamente significativo; esto ha sido especialmente destacable en diferentes especies de gaviotas. Los torrentes cercanos a la conurbación de Palma se han visto ocupados por aves limícolas que han aprovechado la ausencia de seres humanos para alimentarse (evidentemente con la desescalada están desapareciendo de nuevo). Igualmente se han realizado avistamientos de cetáceos en zonas que normalmente no son frecuentadas por estos, incluso dentro de la Bahía de Palma en zonas muy cercanas a la ribera de la mar. En el Parque Nacional Marítimo-terrestre del Archipiélago de Cabrera ha nidificado el águila pescadora (Pandion haliaetus) en lugares donde nunca se había reportado.

Sin embargo, no son estos los únicos fenómenos contabilizados, en Baleares la generación de residuos municipales ha disminuido un $14 \%$ desde la entrada en 
vigor del estado de alarma. Curiosamente la recogida selectiva de papel y cartón es la que más se ha acentuado, con una caída del $19 \%$.

Es posible que, en las condiciones del confinamiento, la disminución del consumo de determinados bienes, el cambio de hábitos de adquisición de bienes de primera necesidad en comercios de proximidad menos procesados y más frescos, y la imposibilidad de consumir determinados bienes prescindibles, han provocado esta disminución en la generación de residuos, ni siquiera las posibles compras en línea han podido contrarrestar los datos de este indicador.

El consumo global en Baleares también ha disminuido, al contrario de los datos que parecen apuntar otras comunidades autónomas, existiendo una correlación entre ambas circunstancias. Así hasta el día 20 de abril en las Islas Baleares se han generado 59.038 toneladas de residuos municipales, un $14 \%$ menos que en los mismos datos que el año pasado, cuando se recogieron 78.666 toneladas. Por islas, se observa una bajada más acusada en las Pitiusas. Así, en Ibiza la caída ha sido del $22 \%$ mientras que en Formentera lo ha sido del 18\%. Menorca, con un $6 \%$, es la isla con una menor reducción de los residuos municipales mientras que Mallorca registra una caída del 14\%. Estos datos reflejan la recogida de residuos en términos absolutos. La recogida selectiva, sin embargo, también ha registrado cifras inferiores a las del año pasado. En concreto, en líneas generales, ha disminuido un $11 \%$. Por fracciones, la caída más acusada la han sufrido el papel y el cartón (19\%) seguido de la materia orgánica (12\%) y los envases de vidrio (11\%). Los envases ligeros, en cambio, han experimentado un incremento del $2 \%$. En cuanto a la fracción de rechazo se han generado 17.209 toneladas menos, una cifra que supone una bajada del $15 \%$.

Fuentes del Gobierno han vinculado este descenso en la generación de residuos al cierre de los sectores turístico y de la restauración, aunque en ciudades como Palma la disminución guarda una correlación similar en zonas de predominio residencial sin apenas comercios ni hostelería. Esto mismo está sirviendo para plantearse un nuevo paradigma en el que se considera necesario que las medidas de reactivación de la economía prevean la diversificación y circularización de la economía balear. Igualmente, si la disminución estuviera vinculada al cierre de los establecimientos de hostelería (bares, cafeterías y restaurantes), ello nos debería hacer reflexionar sobre el mayor impacto del 
consumo en estos establecimientos con respecto a los consumos sustitutivos en los domicilios particulares, algo que ya sabíamos: un mismo objetivo (la comida familiar de mediodía, por ejemplo) genera un mayor número de residuos cuando se produce en un restaurante o una cafetería que cuando se realiza en un domicilio particular. Esta tendencia en el cambio de modelo debería servir para poder hacer frente a futuras crisis y seguir avanzando hacia un escenario que implique la disminución en la generación de residuos sin que ello sea debido a circunstancias extraordinarias como las derivadas de la pandemia. La economía circular y el cambio de hábitos deberían orientar nuestro futuro y el de la normativa ambiental post COVID-19.

La cuestión que se suscita es: ¿podríamos vivir el resto del año manteniendo este mismo impacto sobre el consumo y los recursos del planeta? La respuesta queda en el aire y en manos de la "nueva normalidad". 
JOSÉ MANUEL GÓMEZ GONZÁLEZ

Cap del Servei Jurídic d’Ordenació del Territori

Departament de Territori i Infraestructures. Consell Insular de Mallorca 
Sumari: 1. Introducció. 2. Mesures urgents per a la reactivació econòmica després de la COVID19. 3. Modificació i Text refós de la Llei 12/2016 d'avaluació ambiental. 4. Efectes de l'estat d'alarma en el medi ambient.

\section{INTRODUCCIÓ}

No cal insistir gaire en el fet que la pandèmia provocada pel SARS-CoV-2 ha condicionat completament l'activitat normativa ambiental també a les llles Balears. Si tenim en compte que les grans iniciatives ja es van aprovar abans de tancar el 2019 i es van relatar en la crònica corresponent, i que a penes ha pogut arrancar el curs parlamentari del primer quadrimestre del 2020, tenim molt poc material per redactar l'apartat sobre les polítiques ambientals del semestre, encara que sigui retardant al màxim el Iliurament d'aquesta crònica. La majoria de les accions s'han destinat al tractament de la pandèmia, i els esborranys de disposicions que s'estan preparant per a la tornada a la "nova normalitat" sembla que deixen de banda per complet la dimensió ambiental, atès que la recuperació i la diversificació econòmica prevalen per sobre de tota la resta. Segurament en la propera crònica tindrem espai i temps per analitzar el que ens ve a sobre, però per la poca cosa que he pogut veure en mans de funcionaris, serà la revelació d'un enorme despropòsit ambiental amb el qual haurem de bregar. No serà ni la primera vegada ni l'última que per sortir d'una crisi la gran víctima acabi sent el nostre entorn, el medi en el qual vivim. L'emergència climàtica serà solament un ressò llunyà i afeblit, i els anomenats "nous paradigmes", un simple miratge.

Vegem, doncs, les escasses novetats que podem destacar en l'escenari estrany i excepcional d'aquest semestre.

\section{MESURES URGENTS PER A LA REACTIVACIÓ ECONÒMICA DESPRÉS DE LA COVID-19}

Sobre aquesta qüestió, a penes podem remetre'ns a les cròniques periodístiques parlamentàries, al visionament de les discussions en el Ple del Parlament i al que s'ha manifestat en rodes de premsa, però s'ha fet públic que el Govern de la comunitat autònoma està preparant la redacció d'un decret llei de mesures urgents destinat a reactivar l'economia i a pal-liar els perjudicis econòmics i 
socials de la COVID-19. En el document s'incorporaran un seguit de propostes de simplificació i agilitació administrativa, de regularització d'activitats i instal·lacions, d'incentivació de projectes industrials estratègics i de diversificació econòmica, amb la intenció inicial de reduir la forta dependència econòmica del sector turístic, en termes de PIB. També és cert que es mouen ajudes i mesures que pretenen obtenir les capes més vulnerables de la societat.

Com hem apuntat, en una pròxima crònica haurem d'analitzar les conseqüències que tot això comportarà al medi ambient $\mathrm{i}$, especialment, pel que fa a la normativa de protecció. Una de les tendències que s'apunten en el decret llei és l'ordenació directa d'aspectes territorials, urbanístics i d'ordre sectorial, que alternarà la sistemàtica clàssica basada en instruments articulats al voltant d'un sistema jeràrquic compost per subsistemes dependents. L'experiència ens mostra que alterar qualsevol disposició sistemàtica i interdependent comporta oblits, antinòmies, conflictes normatius i superposició de supòsits; probablement això és el que també succeirà ara.

\section{MODIFICACIÓ I TEXT REFÓS DE LA LLEI 12/2016 D’AVALUACIÓ} AMBIENTAL

La disposició final tercera de la Llei 9/2018, de 31 de juliol, per la qual es va modificar la Llei 12/2016, de 17 d'agost, d'avaluació ambiental de les llles Balears, obligava a redactar un text refós d'aquesta llei, text que va començar a redactar-se a la fi de 2019 i que incorporava el contingut de la Sentència del Tribunal Constitucional de 3 d'octubre de 2019, havent corregit uns aspectes puntuals de la llei per motius competencials derivats de la legislació bàsica estatal en la matèria.

El mateix octubre de 2019 es va iniciar un tràmit d'informació pública sobre la proposta del text refós, que ara es veurà alterada per algunes modificacions que acompanyaran el decret llei en redacció. Aquest text refós començava a ser necessari malgrat la joventut de la norma, i és que la veritat és que la dinàmica legislativa instal·lada en aquesta comunitat autònoma implica una hiperactivitat normativa que genera canvis continuats en la legislació fins al punt que costa molt saber en cada cas quin règim impera; i no només això, el gran problema 
són els conflictes de normes que apareixen, tal com hem apuntat en l'apartat anterior. El negoci dels textos consolidats i comentats es troba en auge.

\section{EFECTES DE L’ESTAT D'ALARMA EN EL MEDI AMBIENT}

Un altre dels efectes experimentats al llarg d'aquests mesos és la regeneració de determinats béns ambientals. L'aturada feta a conseqüència del confinament ordenat per la declaració de l'estat d'alarma ha provocat una disminució significativa de la contaminació atmosfèrica, la recuperació d'entorns naturals i seminaturals, especialment als voltants de les ciutats i pobles, així com la millora en hàbitats sensibles a la fauna, especialment en zones de cria i reproducció d'ocells.

Bona part d'aquests efectes s'han posat de manifest en els nostres espais naturals protegits, on l'absència de freqüentació humana està provocant un repartiment territorial més gran de la fauna. S'han detectat moviments de fauna silvestre en llocs on feia anys que no n'hi havia; es reporta canvi d'hàbits d'alimentació d'ocells marins, atès que l'aturada ha provocat un efecte reserva en aquesta època de l'any veritablement significatiu; això ha estat especialment destacable en diferents espècies de gavines. Els torrents pròxims a la conurbació de Palma s'han vist ocupats per ocells limícoles que han aprofitat l'absència d'éssers humans per alimentar-se (evidentment amb la desescalada estan desapareixent de nou). Igualment s'han fet albiraments de cetacis en zones que normalment no freqüenten, fins i tot a la badia de Palma, en zones molt pròximes a la ribera de la mar. Al Parc Nacional Maritimoterrestre de l'Arxipèlag de Cabrera ha nidificat l'àguila pescadora (Pandion haliaetus) en llocs on mai ho havia fet.

No obstant això, no són aquests els únics fenòmens que s'han comptabilitzat. $A$ les Balears la generació de residus municipals ha disminuït un $14 \%$ des de l'entrada en vigor de l'estat d'alarma. Curiosament la recollida selectiva de paper i cartó és la que més s'ha accentuat, amb una caiguda del 19\%.

És possible que en les condicions del confinament, la disminució del consum de determinats béns, el canvi d'hàbits d'adquisició de béns de primera necessitat en comerços de proximitat menys processats i més frescos, i la impossibilitat de consumir determinats béns prescindibles, han provocat aquesta disminució en la 
generació de residus. Ni tan sols les possibles compres en línia han pogut contrarestar les dades d'aquest indicador.

El consum global a les Balears també ha disminuït, al contrari de les dades que apunten altres comunitats autònomes, havent-hi una correlació entre totes dues circumstàncies. Així, fins al dia 20 d'abril a les Illes Balears s'han generat 59.038 tones de residus municipals, un $14 \%$ menys que en les mateixes dades que l'any passat, quan se'n van recollir 78.666 tones. Per illes, s'observa una baixada més acusada a les Pitiüses. Així, a Eivissa, la caiguda ha estat del $22 \%$ mentre que a Formentera ha estat del 18\%. Menorca, amb un $6 \%$, és l'illa amb més reducció dels residus municipals, mentre que Mallorca registra una caiguda del $14 \%$. Aquestes dades reflecteixen la recollida de residus en termes absoluts. La recollida selectiva, no obstant això, també ha registrat xifres inferiors a les de l'any passat. En concret, en línies generals, ha disminuït un 11\%. Per fraccions, la caiguda més acusada l'han experimentat el paper i el cartó (19\%), seguits de la matèria orgànica (12\%) i els envasos de vidre (11\%). Els envasos lleugers, en canvi, han experimentat un increment del $2 \%$. Quant a la fracció de rebuig, s'han generat 17.209 tones menys, una xifra que suposa una baixada del $15 \%$.

Fonts del Govern han vinculat aquest descens en la generació de residus al tancament dels sectors turístic i de la restauració, encara que en ciutats com Palma la disminució manté una correlació similar en zones de predomini residencial sense tot just comerços ni hostaleria. Això mateix està servint per plantejar-se un nou paradigma en el qual es considera necessari que les mesures de reactivació de l'economia prevegin la diversificació i circularització de l'economia balear. Igualment, si la disminució estigués vinculada al tancament dels establiments d'hostaleria (bars, cafeteries i restaurants), això ens hauria de fer reflexionar sobre l'impacte més gran del consum en aquests establiments respecte als consums substitutius en els domicilis particulars, alguna cosa que ja sabíem: un mateix objectiu (el menjar familiar de migdia, per exemple) genera més residus quan té lloc en un restaurant o en una cafeteria que quan es du a terme en un domicili particular. Aquesta tendència en el canvi de model hauria de servir per poder fer front a futures crisis i continuar avançant cap a un escenari que impliqui la disminució en la generació de residus sense que això es degui a circumstàncies extraordinàries com les derivades de la pandèmia. L'economia 
circular i el canvi d'hàbits haurien d'orientar el nostre futur i el de la normativa ambiental post-COVID-19.

La qüestió que se suscita és: podríem viure la resta de l'any, mantenint aquest mateix impacte en el consum i els recursos del planeta? La resposta queda enlaire i en mans de la "nova normalitat". 
